\title{
Validity of self-reported height and weight and derived body mass index in middle-aged and elderly individuals in Australia
}

\author{
Suan Peng Ng, Rosemary Korda, Mark Clements, Isabel Latz \\ National Centre for Epidemiology and Population Health, \\ Australian National University, Australian Capital Territory
}

\section{Adrian Bauman}

School of Public Health, University of Sydney, New South Wales

\section{Hilary Bambrick \\ National Centre for Epidemiology and Population Health, Australian National University, Australian Capital Territory and School of Medicine, University of Western Sydney, New South Wales}

\section{Bette Liu}

School of Medicine, University of Western Sydney, New South Wales and Faculty of Medicine, University of New South Wales

\section{Kris Rogers, Nicol Herbert}

The Sax Institute, New South Wales

\section{Emily Banks}

National Centre for Epidemiology and Population Health, Australian National University, Australian Capital Territory and The Sax Institute, New South Wales

B ody mass index (BMI, weight in kilograms divided by square of height in metres) provides a useful and internationally recognised measure of adiposity. Self-reported measures of height and weight are often used to estimate BMI, as obtaining directly measured anthropometric data for all individuals can be impractical and costly, particularly in large-scale studies. ${ }^{1}$

Previous studies have demonstrated that self-reported height and weight correlate well with measured values, ${ }^{1-11}$ although individuals tend to overestimate their height and underestimate their weight..$^{1-5,12-18}$ There is a tendency for greater underestimation of selfreported weight with increasing measured weight, BMI and waist circumference, ${ }^{2-5,12-19}$ and shorter individuals are more likely than taller individuals to overestimate their height. ${ }^{2,3}$ Women are likely to underreport their weight to a greater extent than men. ${ }^{1,67,713,18,20-23}$

BMI derived from self-reported measures, although slightly underestimated, has been shown to be reliable for ranking study participants and hence provides a useful measure for epidemiological, particularly aetiological, research. Studies using BMI based on self-reported measures have provided valuable insights into the health effects of obesity and overweight, particularly in relation to mortality ${ }^{24}$ and cancer incidence..$^{25}$

While previous studies have shown good correlation between measured and self-reported BMI elsewhere, there is little information about the relationship between

Submitted: September $2010 \quad$ Revision requested: January $2011 \quad$ Accepted: April 2011 Correspondence to:

Prof. Emily Banks, National Centre for Epidemiology and Population Health, Australian National University, Canberra ACT 0200; e-mail: Emily.Banks@anu.edu.au

\begin{abstract}
Background: Body mass index (BMI) is an important measure of adiposity. While BMI derived from self-reported data generally agrees well with that derived from measured values, evidence from Australia
\end{abstract} is limited, particularly for the elderly. Methods: We compared self-reported with measured height and weight in a random sample of 608 individuals aged $\geq 45$ from the 45 and Up Study, an Australian population-based cohort study. We assessed degree of agreement and correlation between measures, and calculated sensitivity and specificity to quantify BMI category misclassification. Results: On average, in males and females respectively, height was overestimated by $1.24 \mathrm{~cm}(95 \% \mathrm{Cl}$ : $0.75-1.72)$ and $0.59 \mathrm{~cm}(0.26-0.92)$; weight was underestimated by $1.68 \mathrm{~kg}$ (-1.99- -1.36) and 1.02kg (-1.24- -0.80); and BMI based on self-reported measures was underestimated by $0.90 \mathrm{~kg} / \mathrm{m} 2(-1.09-$ $-0.70)$ and $0.60 \mathrm{~kg} / \mathrm{m} 2(-0.75--0.45)$. Underestimation increased with increasing measured BMI. There were strong correlations between self-reported and measured height, weight and $\mathrm{BMI}(\mathrm{r}=0.95$, 0.99 and 0.95 , respectively, $p<0.001$ ). While there was excellent agreement between BMI categories from self-reported and measured data (kappa $=0.80$ ), obesity prevalence was underestimated. Findings did not differ substantially between middleaged and elderly participants.

Conclusions: Self-reported data on height and weight quantify body size appropriately in middle-aged and elderly individuals for relative measures, such as quantiles of BMI. However, caution is necessary when reporting on absolute $\mathrm{BMI}$ and standard BMI categories, based on self-reported data, particularly since use of such data is likely to result in underestimation of the prevalence of obesity.

Key words: BMI, weight, height, validity, Australia

Aust NZ J Public Health. 2011; 35:557-63 doi: 10.1111/j.1753-6405.2011.00742.x 
the two in the Australian population, ${ }^{26-28}$ particularly in the elderly. Differences in the validity of self-reported measures among elderly people in comparison with the general population are likely, since physical changes that occur with increasing age also affect individuals' height and weight. Indeed, the results of the few studies that have included specific analyses relating to people above the age of 75 suggest that the discrepancy between BMI based on self-reported and BMI based on measured height and weight increases with age. ${ }^{7,29-32}$ This study compares self-reported and measured height and weight in a population-based sample of men and women aged 45 and over from New South Wales, including elderly individuals. The study uses a variety of analytic tests to compare these measures, and examines the implications for research and public health.

\section{Methods}

\section{Study population}

The 45 and Up Study is a large-scale Australian cohort study of healthy ageing involving more than 265,000 men and women aged 45 and over from New South Wales. Participants in the 45 and Up Study were randomly sampled from the Medicare Australia database, which provides virtually complete coverage of the general population. They joined the study by completing a baseline questionnaire (between February 2006 and October 2008) and giving signed consent for follow-up and linkage of their information to a range of health databases. It is described in detail elsewhere. ${ }^{33}$

Between June and September 2009, a random sample of 2,340 45 and Up Study participants living in either Wagga Wagga (a rural area) or Parramatta (an urban area) were invited to take part in this study. Participants were asked to complete a brief questionnaire and about two weeks later to attend a local clinic or pathology centre to give a blood sample and have a range of physical measures taken, including height, weight and waist circumference. The brief questionnaire requested information about height by asking "How tall are you without shoes?" and on weight by asking "About how much do you weigh?" At the clinic, height was measured using a Charder HM200P stadiometer without shoes and was recorded to the nearest $0.1 \mathrm{~cm}$. Weight was measured in light clothing using a Charder MS-3200 digital scale and recorded to the nearest $0.1 \mathrm{~kg}$. BMI was calculated and where categorised the following ranges were used: low weight -15 to $\leq 19.9 \mathrm{~kg} / \mathrm{m}^{2}$; healthy weight -20.0 to $\leq 24.9 \mathrm{~kg} / \mathrm{m}^{2}$; overweight $\mathrm{t}^{34}-25.0$ to $\leq 29.9 \mathrm{~kg} / \mathrm{m}^{2}$; and obese ${ }^{34}-$ 30 to $50 \mathrm{~kg} / \mathrm{m}^{2}$.

Ethical approval for this study was provided by the University of New South Wales Human Research Ethics Committee and the Australian National University Human Research Ethics Committee.

\section{Statistical analysis}

Self-reported height and weight from the additional brief questionnaire completed during 2009 are used throughout this paper and compared with contemporaneously measured values for height and weight (i.e. measured about two weeks later). A further analysis was conducted to investigate the relationship between self-reported height and weight on the baseline questionnaire completed in 2006-08 with the measured values (i.e. measured some 1-3 years later).

Mean height, weight and BMI were calculated for the selfreported and the measured data. Self-reported and measured data were compared using the Student's paired t-test and the strength of association between them was estimated using Spearman rank correlation coefficients. The extent of absolute agreement between the self-reported and measured data was examined using Bland-Altman ${ }^{35}$ plots. These plots show the differences between self-reported and measured values plotted against the mean of the self-reported and measured values. Limits of agreement were computed as the mean difference $\pm 1.96 \mathrm{sd}$. Non-parametric tests for trend were used to examine the association between mean discrepancies in self-reported and measured data, and quartiles of measured height, quartiles of measured weight, and measured BMI categories, respectively.

BMI classification based on self-reported data was cross-tabulated with BMI based on measured data (the gold standard), and the degree of misclassification in overweight and obesity was assessed

Table 1: Characteristics of the study population.

\begin{tabular}{|c|c|c|c|}
\hline Characteristics & $\begin{array}{c}\text { Male } \\
(n=291)\end{array}$ & $\begin{array}{l}\text { Female } \\
(n=317)\end{array}$ & $\begin{array}{c}\text { Total } \\
(n=608)\end{array}$ \\
\hline \multirow[t]{2}{*}{ Age $\left(\right.$ mean, SD) ${ }^{a}$} & $62.1(9.9)$ & $60.0(9.2)$ & $61.0(9.6)$ \\
\hline & n (\%) & $\mathrm{n}(\%)$ & n (\%) \\
\hline \multicolumn{4}{|l|}{ Age groups (years) ${ }^{a}$} \\
\hline $45-54$ & $77(26.5)$ & $103(32.5)$ & $180(29.6)$ \\
\hline $55-64$ & $103(35.4)$ & $126(39.8)$ & $229(37.7)$ \\
\hline $65-74$ & $70(24.1)$ & $63(19.9)$ & $133(21.9)$ \\
\hline$\geq 75$ & $41(14.1)$ & $25(7.9)$ & $66(10.9)$ \\
\hline \multicolumn{4}{|l|}{ Location } \\
\hline Parramatta & $137(47.1)$ & $157(49.5)$ & $294(48.4)$ \\
\hline Wagga Wagga & $154(52.9)$ & $160(50.5)$ & $314(51.6)$ \\
\hline \multicolumn{4}{|l|}{ Educational status ${ }^{a}$} \\
\hline No qualification & $18(6.2)$ & $28(9.0)$ & $46(7.7)$ \\
\hline School certificate & $47(16.3)$ & $71(22.8)$ & $118(19.6)$ \\
\hline HSC or equivalent & $23(8.0)$ & $31(9.9)$ & $54(9.0)$ \\
\hline Trade/Certificate & $111(38.4)$ & $88(28.2)$ & $199(33.1)$ \\
\hline Tertiary & $90(31.1)$ & $94(30.1)$ & $184(30.6)$ \\
\hline \multicolumn{4}{|c|}{ Height based on self-reported data ${ }^{b}(\mathrm{~cm})$} \\
\hline$<161.0$ & $7(2.4)$ & $136(42.9)$ & $143(23.5)$ \\
\hline 161.0 to $<169.0$ & $30(10.3)$ & $130(41.0)$ & $160(26.3)$ \\
\hline 169.0 to $<177.0$ & $110(37.8)$ & $42(13.3)$ & $152(25.0)$ \\
\hline$\geq 177.0$ & $144(49.5)$ & $9(2.8)$ & $153(25.2)$ \\
\hline \multicolumn{4}{|c|}{ Weight based on self-reported data $(\mathrm{kg})$} \\
\hline$<66.0$ & $20(6.9)$ & $129(40.7)$ & $149(24.5)$ \\
\hline 66.0 to $<78.0$ & $53(18.2)$ & 99 (31.2) & $152(25.0)$ \\
\hline 78.0 to $<88.0$ & $102(35.1)$ & $46(14.5)$ & $148(24.3)$ \\
\hline$\geq 88.0$ & $116(39.9)$ & $43(13.6)$ & $159(26.2)$ \\
\hline \multicolumn{4}{|c|}{ BMI category based on self-reported data $\left(\mathrm{kg} / \mathrm{m}^{2}\right)$} \\
\hline$<20.0$ (low weight) & $8(2.8)$ & $12(3.8)$ & $20(3.3)$ \\
\hline 20.0 to $\leq 24.9$ (healthy weight) & $65(22.3)$ & $114(36.0)$ & $179(29.4)$ \\
\hline 25.0 to $\leq 29.9$ (overweight) & $150(51.6)$ & $112(35.3)$ & $262(43.1)$ \\
\hline$\geq 30.0$ (obese) & $68(23.4)$ & 79 (24.9) & $147(24.2)$ \\
\hline
\end{tabular}


by computing sensitivity, specificity, positive predictive value and negative predictive value. Weighted Cohen's kappa ${ }^{36}$ statistics were used to assess the degree of concordance with categories of BMI (i.e. using Stata's pre-recorded weight of 1 if perfect agreement and 0 otherwise). Statistical significance was set at $p<0.05$. All data analyses were performed using Stata version 10.0 (Stata Corp., College Station, Texas) and separate analyses were done for each sex.

\section{Results}

Completed questionnaires and measurements were received from 762 participants (response rate of 33\%). One hundred and fiftyfour participants were excluded due to missing values $(n=146)$ or invalid height, weight or BMI values $(\mathrm{n}=8$, where height $<100 \mathrm{~cm}$ or $>240 \mathrm{~cm}$; or weight $<35 \mathrm{~kg}$ or $>270 \mathrm{~kg}$; or BMI $<15 \mathrm{~kg} / \mathrm{m}^{2}$ or $>50$ $\mathrm{kg} / \mathrm{m}^{2}$ ), leaving 608 for the analyses reported here. No significant differences in baseline weight $(p=0.25)$ and baseline BMI $(p=0.90)$ based on self-reported values were found between respondents and non-respondents, although participants in the validation study were on average $2 \mathrm{~cm}$ taller than non-respondents $(p=0.001)$.

Table 1 gives the characteristics of the study sample. About half the sample were women (52\%) and ages at resurvey ranged between 45 and 87 years (mean 61 years), with $11 \%$ of participants aged 75 years or older. Reflecting the sampling strategy, there were about equal proportions of urban and rural participants. One-third had tertiary qualifications. The mean BMI based on self-reported height and weight was $27.3 \mathrm{~kg} / \mathrm{m}^{2}$, with $43 \%$ of participants classified as overweight and $24 \%$ obese.

Mean discrepancies and correlations between self-reported and contemporaneously measured height, weight and BMI are shown in Table 2, and Figure 1(a-c) shows the Bland-Altman plots for height, weight and BMI, respectively. Height was overestimated by an average of $0.90 \mathrm{~cm}$ and weight underestimated by an average of $1.34 \mathrm{~kg}$; consequently BMI was underestimated by $0.74 \mathrm{~kg} /$ $\mathrm{m}^{2}$. On average, men overestimated their height by $1.24 \mathrm{~cm}$ and underestimated their weight by $1.68 \mathrm{~kg}$, while women overestimated their height by $0.59 \mathrm{~cm}$ and underestimated their weight by $1.02 \mathrm{~kg}$. As a result, BMI calculated from self-reported height and weight significantly underestimated measured BMI (by $0.90 \mathrm{~kg} / \mathrm{m}^{2}$ and 0.60 $\mathrm{kg} / \mathrm{m}^{2}$ for men and women, respectively). In $95 \%$ of participants, discrepancies in BMI based on measured and self-reported data ranged between underestimation of $3.75 \mathrm{~kg} / \mathrm{m}^{2}$ and overestimation of $2.26 \mathrm{~kg} / \mathrm{m}^{2}$ (Figure 1c). Notably, although there were these discrepancies between self-reported and contemporaneously measured height, weight and BMI, the correlations between these measures were extremely high, at $0.95,0.99$ and 0.95 , respectively (all $p<0.001$ ).

While there were no clear patterns of systematic error for height (Figure 1a) and BMI (Figure 1c), a greater tendency towards underestimation of weight among individuals with greater mean weight was observed in Figure 1(b), and examination of the association between mean discrepancies in self-reported and measured values and quartile of measured categories (Table 3 ) show significant trends. In both men and women, the underestimation of weight and BMI based on self-reported data increased with increasing measured weight and BMI respectively; in men only, overestimation of height based on self-reporting increased with decreasing measured height.

When discrepancies in height, weight and BMI were examined separately by age group in men and women (not shown in tables), there were no significant trends evident except that, among men, the older the participant the greater the extent of height overestimation ( $p$ (trend $)=0.006)$, with the discrepancy ranging from $0.28 \mathrm{~cm}(95 \%$ CI: $-0.62,1.18)$ in those aged $55-64$ years to $2.65 \mathrm{~cm}$ (95\% CI: 1.80 ,

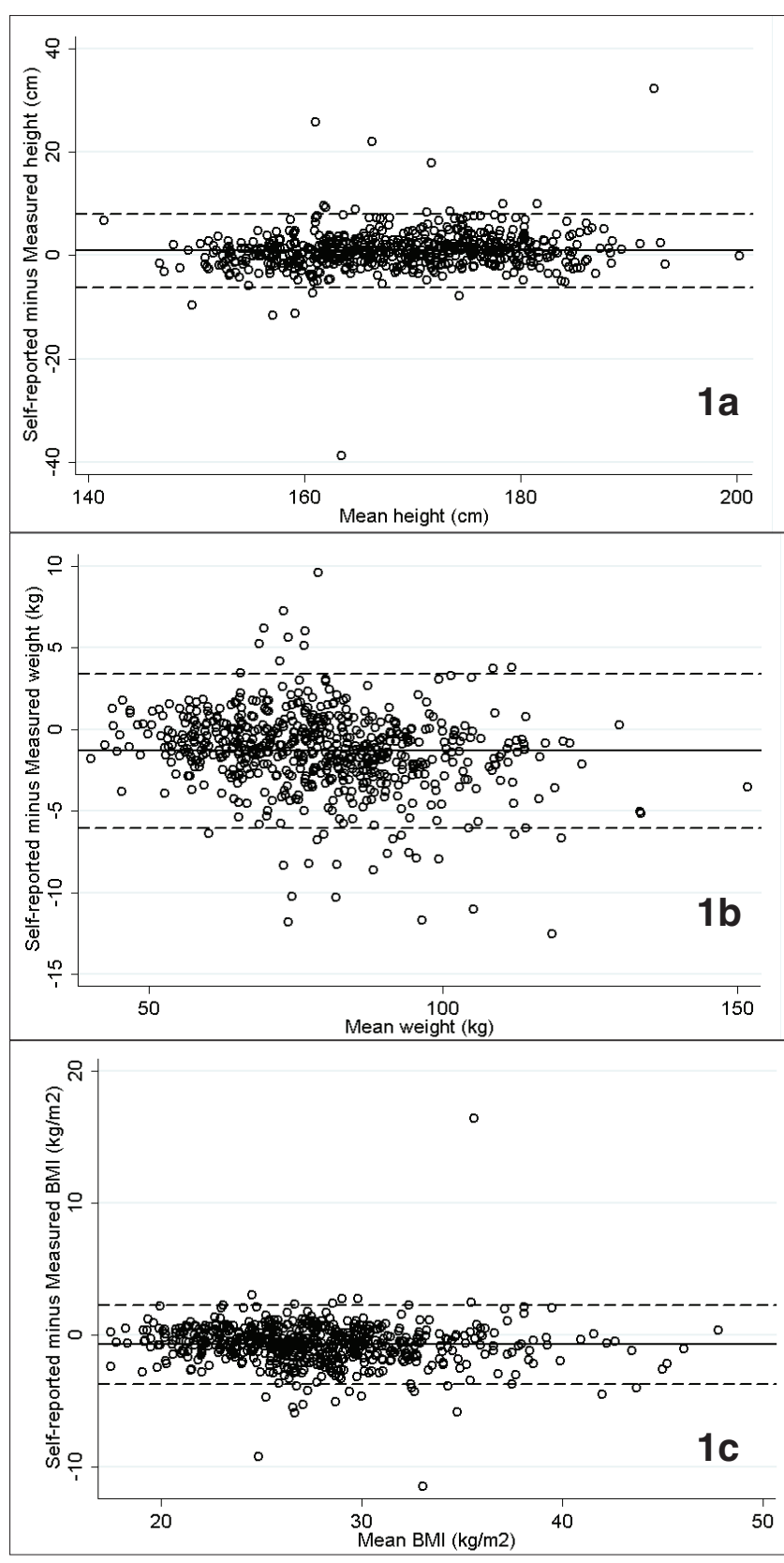

Figure 1a-c: Bland-Altman plots of the discrepancy between self-reported and measured (a) height, (b) weight and (c) BMI versus the mean of self-reported and measured data. Horizontal lines in each figure represent the mean discrepancy (solid line) and $95 \%$ limits of agreement (dashed lines). 


\subsection{0) among those aged 75 years or more.}

When measured height, weight and BMI were compared against self-reported values from the baseline questionnaire completed one to three years earlier, discrepancies in weight and BMI were slightly larger than they were for the contemporaneously measured values, but correlations between self-reported values at baseline and measured height, weight and BMI remained high (Table 4).

When BMI categories (low weight, healthy weight, overweight and obese) based on measured height and weight (the gold standard) were compared with BMI categories based on self-reported data, overall $83 \%$ of participants were correctly classified $(80 \%$ of men and $85 \%$ of women). The weighted kappa value indicated excellent agreement for the whole sample (kappa $=0.80, p<0.001)$ and fair to good agreement for men (kappa $=0.74, p<0.001)$ and excellent agreement for women (kappa $=0.84, p<0.001$ ) (Table 5). Table 6 shows the diagnostic test values (sensitivity, specificity, and positive and negative predictive values) for overweight and obesity classifications based on self-reported height and weight. Sensitivity results indicate that $83 \%$ of those who were overweight and $79 \%$ of those who were obese were identified as such on the basis of self-reported height and weight. Specificity proportions were higher, with $86 \%$ of those who were not overweight being correctly identified as such on the basis of self-report, while $99 \%$ of non-obese people were correctly identified as such. The positive predictive values indicate that $82 \%$ of those who were classified as overweight on the basis of self-report were overweight, while $97 \%$ of those who were classified as obese on self-reported data were obese. Similar proportions were found for negative predictive values. The prevalence of overweight based on self-reported data was comparable to that based on measured values, while the prevalence of obesity based on self-reported height and weight was shown to be underestimated by around $6 \%$.

Table 2: Mean discrepancies and correlations between self-reported and contemporaneously measured height, weight and BMI.

\begin{tabular}{|c|c|c|c|c|}
\hline Variable & $\begin{array}{l}\text { Self-reported on brief } \\
\text { questionnaire } \\
\text { Mean (SD) }\end{array}$ & $\begin{array}{l}\text { Measured } \\
\text { Mean (SD) }\end{array}$ & $\begin{array}{c}\text { Discrepancy } \\
\text { (Self-reported minus Measured) } \\
\text { Mean }(95 \% \mathrm{Cl})^{\mathrm{a}}\end{array}$ & $\begin{array}{c}\text { Correlation } \\
(95 \% \mathrm{Cl})\end{array}$ \\
\hline \multicolumn{5}{|c|}{ Height (cm) } \\
\hline Men & $176.26(7.36)$ & $175.03(6.79)$ & $1.24(0.75-1.72)$ & $0.88(0.85-0.90)$ \\
\hline Women & $162.21(6.88)$ & $161.62(6.26)$ & $0.59(0.26-0.92)$ & $0.89(0.87-0.91)$ \\
\hline Total & $168.94(10.00)$ & $168.04(9.35)$ & $0.90(0.61-1.19)$ & $0.95(0.94-0.95)$ \\
\hline \multicolumn{5}{|c|}{ Weight (kg) } \\
\hline Men & $85.82(13.71)$ & $87.50(14.47)$ & $-1.68(-1.99--1.36)$ & $0.98(0.97-0.98)$ \\
\hline Women & $71.43(15.66)$ & $72.45(15.88)$ & $-1.02(-1.24--0.80)$ & $0.99(0.98-0.99)$ \\
\hline Total & $78.32(16.41)$ & $79.65(16.97)$ & $-1.34(-1.53--1.14)$ & $0.99(0.99-0.99)$ \\
\hline \multicolumn{5}{|c|}{$\mathrm{BMI}\left(\mathrm{kg} / \mathrm{m}^{2}\right)$} \\
\hline Men & $27.61(4.10)$ & $28.51(4.13)$ & $-0.90(-1.09--0.70)$ & $0.91(0.89-0.93)$ \\
\hline Women & $27.08(5.28)$ & $27.68(5.54)$ & $-0.60(-0.75--0.45)$ & $0.97(0.96-0.97)$ \\
\hline Total & $27.33(4.76)$ & 28.08 (4.93) & $-0.74(-0.87--0.62)$ & $0.95(0.94-0.95)$ \\
\hline
\end{tabular}

Notes:

a. $p<0.05$ ( $p$-values from paired t-tests).

Table 3: Mean discrepancy between self-reported and contemporaneously measured height, weight and BMI by measured height and weight quartiles and BMI categories.

\begin{tabular}{|c|c|c|c|c|}
\hline \multirow[t]{3}{*}{ Variables } & \multicolumn{2}{|c|}{ Men } & \multicolumn{2}{|c|}{ Women } \\
\hline & \multicolumn{2}{|c|}{ Discrepancy (Self-reported minus Measured) } & \multicolumn{2}{|c|}{ Discrepancy (Self-reported minus Measured) } \\
\hline & Mean $(95 \% \mathrm{Cl})$ & $p$ value $^{a}$ & Mean $(95 \% \mathrm{Cl})$ & $p$ value $^{a}$ \\
\hline Measured height $(\mathrm{cm})$ & & 0.043 & & 0.264 \\
\hline$<161.0$ & $5.58(-5.29-16.45)$ & & $0.72(0.13-1.30)$ & \\
\hline 161.0 to $<168.0$ & $1.74(0.46-3.01)$ & & $0.29(-0.19-0.77)$ & \\
\hline 168.0 to $<174.9$ & $1.35(0.83-1.88)$ & & $1.03(0.31-1.74)$ & \\
\hline Measured weight $(\mathrm{kg})$ & & $<0.001$ & & 0.001 \\
\hline$<67.0$ & $-0.47(-1.47-0.53)$ & & $-0.59(-0.83--0.35)$ & \\
\hline 67.0 to $<78.7$ & $0.00(-0.81-0.81)$ & & $-1.21(-1.70--0.71)$ & \\
\hline 78.7 to $<89.9$ & $-1.86(-2.27--1.45)$ & & $-1.58(-2.17--0.99)$ & \\
\hline$\geq 89.9 \mathrm{~kg}$ & $-2.54(-3.05--2.03)$ & & $-1.33(-2.05--0.61)$ & \\
\hline Measured BMI category $\left(\mathrm{kg} / \mathrm{m}^{2}\right)$ & & $<0.001$ & & $<0.001$ \\
\hline 20.0 to $\leq 24.9$ & $-0.39(-0.65--0.14)$ & & $-0.24(-0.41--0.07)$ & \\
\hline 25.0 to $\leq 29.9$ & $-0.81(-1.13--0.50)$ & & $-0.59(-0.82--0.35)$ & \\
\hline$\geq 30.0$ & $-1.33(-1.65--1.01)$ & & $-1.12(-1.48--0.77)$ & \\
\hline
\end{tabular}

Notes:

a. $p$-value for non-parametric test for trend. 


\section{Discussion}

This study shows that self-reported data about height and weight are generally appropriate for calculating BMI in middle-aged and older Australian adults, particularly where these data are used for studies comparing outcomes based on quantiles of BMI. Although individuals tend to overestimate their height and underestimate their weight, the mean differences between self-reported and measured values are not large and the correlations between self-reported and measured anthropometrics are extremely high. However, selfreported data are less appropriate for estimating the population prevalence of overweight and obesity.

Our findings are consistent with previous studies that show high correlations between self-reported and measured anthropometric values, ${ }^{1-11}$ even though individuals tend to overestimate their height and underestimate their weight (and hence BMI). ${ }^{1-5,12-18}$ The tendency for greater discrepancy between the self-reported and measured values with increasing measured weight and BMI and decreasing height found in this study has also been reported previously. ${ }^{2-5,12-19,30,37,38}$ However, unlike previous studies that have found women are likely to under-report their weight to a greater extent than men, , $^{1,6-7,13,18,20-23}$ we found, if anything, that men under- reported their weight to a greater extent than women. The sensitivity and specificity of BMI classifications of obesity and overweight, particularly informative for researchers using self-reported data to classify patients into BMI categories, was also comparable to that found in other studies. ${ }^{9-10,19}$ The overall rate of misclassification of BMI category in our validation study of an older cohort, at $17 \%$, was similar to a rate of $20 \%$ in the most recent Australian National Health Survey of adults aged 18 years and over. ${ }^{28}$

We found self-reported height and weight measures to be valid in the older population, with no systematic age difference in discrepancies between self-reported and measured BMI, although older men overestimated their height by a greater amount than younger men, a finding also consistent with the findings from larger international studies. ${ }^{2,18,19,31}$ The increasing discrepancy between reported and measured height with increasing age may be explained by height loss. At older ages, height decreases from $1 \mathrm{~cm}$ to $2 \mathrm{~cm}$ per decade as the result of vertebral compression, loss of muscle tone and postural slump, ${ }^{31}$ and participants may be recalling their height from when they were younger. ${ }^{27}$

The near-perfect correlations between self-reported and measured height and weight means that self-reported data should be generally

\begin{tabular}{|c|c|c|c|c|}
\hline Variable & $\begin{array}{l}\text { Self-reported at } \\
\text { baseline } \\
\text { Mean (SD) }\end{array}$ & $\begin{array}{l}\text { Measured } \\
\text { Mean (SD) }\end{array}$ & $\begin{array}{c}\text { Discrepancy } \\
\text { (Self-reported minus Measured) } \\
\text { Mean }(95 \% \mathrm{CI})^{\mathrm{a}}\end{array}$ & $\begin{array}{l}\text { Correlation } \\
(95 \% \mathrm{Cl})\end{array}$ \\
\hline \multicolumn{5}{|l|}{ Height (cm) } \\
\hline Men & $176.05(9.31)$ & $175.10(6.87)$ & $0.95(0.13-1.77)$ & $0.88(0.85-0.90)$ \\
\hline Women & $162.61(6.79)$ & $161.73(6.20)$ & $0.88(0.52-1.23)$ & $0.88(0.85-0.90)$ \\
\hline Total & $169.10(10.52)$ & $168.19(9.34)$ & $0.91(0.48-1.35)$ & $0.93(0.92-0.94)$ \\
\hline \multicolumn{5}{|l|}{ Weight (kg) } \\
\hline Men & $85.18(13.55)$ & $87.53(14.56)$ & $-2.35(-2.83--1.87)$ & $0.95(0.94-0.96)$ \\
\hline Women & 70.77 (15.79) & $72.32(15.82)$ & $-1.55(-2.35--0.76)$ & $0.95(0.93-0.96)$ \\
\hline Total & $77.70(16.41)$ & $79.64(17.01)$ & $-1.94(-2.41--1.46)$ & $0.96(0.95-0.96)$ \\
\hline \multicolumn{5}{|c|}{ BMI $\left(\mathrm{kg} / \mathrm{m}^{2}\right)$} \\
\hline Men & $27.31(3.88)$ & $28.48(4.15)$ & $-1.17(-1.37--0.98)$ & $0.89(0.86-0.91)$ \\
\hline Total & 27.05 (4.66) & 28.14 (4.92) & $-1.09(-1.24--0.93)$ & $0.92(0.91-0.93)$ \\
\hline
\end{tabular}

Notes:

a. $p<0.05$ ( $p$-values from paired $t$-tests).

Table 5: Classification of study population according to self-reported and contemporaneously measured BMI categories, by sex.

Measured BMI category $\left(\mathrm{kg} / \mathrm{m}^{2}\right) \quad$ BMI category based on self-reported height and weight $\left(\mathrm{kg} / \mathrm{m}^{2}\right) \quad$ Weighted $\mathrm{kappa}(95 \% \mathrm{Cl})$

\begin{tabular}{|c|c|c|c|c|c|}
\hline & $<20.0$ & 20.0 to $\leq 24.9$ & 25.0 to $\leq 29.9$ & $\geq \mathbf{3 0 . 0}$ & \\
\hline Men $(n=291)$ & & & & & $0.74(0.71-0.77)^{\mathrm{a}}$ \\
\hline$<20.0$ & 2 & 0 & 0 & 0 & \\
\hline 20.0 to $\leq 24.9$ & 6 & 40 & 3 & 0 & \\
\hline 25.0 to $\leq 29.9$ & 0 & 24 & 126 & 2 & \\
\hline$\geq 30.0$ & 0 & 1 & 21 & 66 & \\
\hline Women $(n=317)$ & & & & & $0.84(0.80-0.85)^{\mathrm{a}}$ \\
\hline$<20.0$ & 7 & 2 & 0 & 0 & \\
\hline 20.0 to $\leq 24.9$ & 5 & 98 & 7 & 0 & \\
\hline 25.0 to $\leq 29.9$ & 0 & 14 & 88 & 3 & \\
\hline$\geq 30.0$ & 0 & 0 & 17 & 76 & \\
\hline
\end{tabular}

$\geq 30.0$

Agreement between self-reported and measured BMI categories is represented by the diagonal cells.

a. $p<0.001$ ( $p$-values from kappa test). 
acceptable for research investigating the relative risks of disease and other health outcomes comparing different quantiles of BMI. This is particularly useful for aetiological research, for example, examining the relationship between BMI and the risk of certain diseases where dose-response relationships provide some indication of the magnitude of the risk and likely causality. To account for measurement error in this approach it may also be valuable to calibrate each quantile using the mean or median of measured values from a random sample of participants. ${ }^{39}$ In addition, in estimating relative risks according to BMI, regression dilution bias may need to be considered. ${ }^{40}$

The absolute differences between self-reported and measured height and weight, while small, mean that any inferences focusing on the absolute values of BMI based on self-reported data must be made carefully, factoring in the likely measurement error and whether this is of clinical significance. This caution also applies to estimation of relative risks based on standard BMI categories. Specifically, while only a small percentage of people classified as obese using self-reported data are misclassified, nearly one in five of those classified as overweight are incorrectly classified, which may bias some findings. In particular, because most of those misclassified in the overweight group were actually likely to be obese, where a positive relationship between increasing BMI and disease is found, estimates based on self-report may overestimate, to some extent, the health risks associated with being obese. Furthermore, this misclassification means the prevalence of overweight and, in particular, obesity, is likely to be underestimated in studies that rely on self-report.

To the best of our knowledge, this validity study of self-reported anthropometric data is the largest undertaken in Australia in recent years that focuses on middle-aged and elderly individuals. A number of limitations should be borne in mind. The response rate was relatively low, as participants were asked to attend a local collection centre and to give a blood sample, as well as having physical measurements. While we cannot exclude the possibility that these study participants may report their heights and weights more accurately than the general Australian population, experience with cohort studies has demonstrated that findings based on internal comparisons tend to be generalisable even when the cohort is not strictly representative. ${ }^{41-43}$ Moreover, empirical work using data from the 45 and Up Study has demonstrated the comparability of relative risk estimates from this study and the more representative NSW Population Health Survey. ${ }^{42}$ The consistency of our results with those of previous studies is also reassuring. We did not subtract any weight from clinic measures to allow for clothing, as other researchers have done, ${ }^{27}$ nor did we account for other factors that might influence height and weight, such as whether or not participants had eaten and the time of day. ${ }^{2}$ If individuals generally measure their weight unclothed and/or prior to eating, then clothing and/or food could be contributing to the weight discrepancies observed here. The information leaflet for the study, given before completing the brief additional questionnaire and attending to give a blood sample and provide anthropometric measures, gave details of clinic procedures, including the fact that height and weight would be measured. It may be that participants reported their height and weight more accurately, knowing they would be measured later. However, the information about measurement was given in the context of the larger study, including information about blood donation and genetic tests. Moreover, self-reported values at baseline, some one to three years before measurement, show very high correlations and relatively small discrepancies between self-reported and measured values, especially when the potential for changes in weight over the one to three year intervening period is considered.

\section{Conclusion}

The ageing of the population in most industrialised, and many less industrialised, countries and the global obesity epidemic means

Table 6: Sensitivity, specificity, positive predictive value (PPV) and negative predictive value (NPV) (95\% Cl) of overweight and obesity classifications based on self-reported height and weight using contemporaneously measured BMI as the gold standard, and prevalence based on BMI estimated from self-reported versus contemporaneously measured values.

\section{Diagnostic test values}

Sensitivity Specificity PPV

\section{Prevalence}

Measured Self-reported values

\begin{tabular}{|c|c|c|c|c|c|c|}
\hline & & & & & & \\
\hline \multicolumn{7}{|c|}{ Measured BMI as gold standard } \\
\hline \multicolumn{7}{|c|}{ Overweight $\left(25.0 \leq \mathrm{BMI} \leq 29.9 \mathrm{~kg} / \mathrm{m}^{2}\right)$} \\
\hline \multirow[t]{2}{*}{ Men } & $82.9 \%$ & $82.7 \%$ & $84.0 \%$ & $81.6 \%$ & $52.0 \%$ & $51.5 \%$ \\
\hline & $(76.0-88.5 \%)$ & $(75.4-88.6 \%)$ & $(77.1-89.5 \%)$ & $(74.2-87.6 \%)$ & & \\
\hline \multirow[t]{2}{*}{ Women } & $83.8 \%$ & $88.7 \%$ & $78.6 \%$ & $91.7 \%$ & $33.1 \%$ & $35.3 \%$ \\
\hline & $(75.3-90.3 \%)$ & $(83.6-92.6 \%)$ & $(69.8-85.8 \%)$ & $(87.1-95.1 \%)$ & & \\
\hline \multirow[t]{2}{*}{ Total } & $83.3 \%$ & $86.3 \%$ & $81.7 \%$ & $87.6 \%$ & $42.3 \%$ & $43.1 \%$ \\
\hline & $(78.1-87.6 \%)$ & $(82.3-89.7 \%)$ & $(76.5-86.2 \%)$ & $(83.6-90.9 \%)$ & & \\
\hline \multicolumn{7}{|c|}{ Obese (BMI $\left.\geq 30 \mathrm{~kg} / \mathrm{m}^{2}\right)$} \\
\hline \multirow[t]{2}{*}{ Men } & $75.0 \%$ & $99.0 \%$ & $97.1 \%$ & $90.1 \%$ & $30.2 \%$ & $23.4 \%$ \\
\hline & $(64.6-83.6 \%)$ & $(96.5-99.9 \%)$ & $(89.8-99.6 \%)$ & $(85.4-93.7 \%)$ & & \\
\hline \multirow[t]{2}{*}{ Women } & $81.7 \%$ & $98.7 \%$ & $96.2 \%$ & $92.9 \%$ & $29.3 \%$ & $24.9 \%$ \\
\hline & $(72.4-89.0 \%)$ & $(96.1-99.7 \%)$ & $(89.3-99.2 \%)$ & $(88.8-95.8 \%)$ & & \\
\hline \multirow[t]{2}{*}{ Total } & $78.5 \%$ & $98.8 \%$ & $96.6 \%$ & $91.5 \%$ & $29.8 \%$ & $24.2 \%$ \\
\hline & (71.7-84.2\%) & $(97.3-99.6 \%)$ & (92.2-98.9\%) & (88.6-93.9\%) & & \\
\hline
\end{tabular}


there is a specific need for reliable self-reported information to be used when investigating and monitoring health in later life. While researchers are often critical of self-reported measures on technical grounds, the results of our study suggest that self-reported height and weight provide valid measures for calculating BMI in this midage and older-age population, particularly where the information is used to compare risk according to quantiles of BMI, which is useful for aetiological research. However, use of self-reported data is likely to underestimate the prevalence of overweight and obesity. Future studies based on self-reported measures of height and weight would benefit from incorporating quantitative consideration of the associated measurement error.

\section{Acknowledgements}

The authors thank the men and women participating in the 45 and Up Study. The Study is managed by The Sax Institute in collaboration with major partner Cancer Council New South Wales; and partners the National Heart Foundation of Australia (NSW Division); NSW Health; beyondblue: the national depression initiative; Ageing, Disability and Home Care, Department of Human Services NSW; and UnitingCare Ageing. This specific project was supported by The Cancer Council NSW and The National Health and Medical Research Council (grant no. 585402). Emily Banks, Mark Clements and Bette Liu are supported by the National Health and Medical Research Council.

\section{References}

1. Gorber S, Tremblay M, Moher D, Gorber B. A comparison of direct vs. self-report measures for assessing height weight and body mass index: a systematic review. Obes Rev. 2007;8(4):307-26.

2. Spencer E, Appleby P, Davey G, Key T. Validity of self-reported height and weight in 4808 EPIC-Oxford participants. Public Health Nutr. 2002;5(4):561-5.

3. Nakamura K, Hoshino Y, Kodama K, Yamamoto M. Reliability of self-reported body height and weight of adult Japanese women. J Biosoc Sci. 1999;31(4):555-8.

4. Wada K, Tamakoshi K, Tsunekawa T, et al. Validity of self-reported height and weight in a Japanese workplace population. Int J Obes. 2005;29(9):1093-9.

5. Dekkers J, Van Wier M, Hendriksen I, Twisk J, Van Mechelen W. Accuracy of self-reported body weight, height and waist circumference in a Dutch overweight working population. BMC Med Res Methodol. 2008;8:69.

6. Imrhan S, Imrhan V, Hart C. Can self-estimates of body weight and height be used in place of measurements for college students? Ergonomics. 1996;39(12):144553.

7. Avila-Funes J, Gutierrez-Robledo L, Ponce De Leon Rosales S. Validity of height and weight self-report in Mexican adults: results from the national health and aging study. J Nutr Health Aging. 2004;8(5):355-61.

8. Huber L. Validity of self-reported height and weight in women of reproductive age. Matern Child Health J. 2007;11(2):137-44.

9. Fonseca MJ, Faerstein E, Chor D, Lopes CS. Validity of self-reported weight and height and the body mass index within the "Pró-saúde" study. Rev Saude Publica. 2004;38(3):392-8.

10. Lim LLY, Seubsman S, Sleigh A. Validity of self-reported weight, height, and body mass index among university students in Thailand: Implications for population studies of obesity in developing countries. Population Health Metric. 2009;7:15.

11. Bolton-Smith C, Woodward M, Tunstall-Pedoe H, Morrison C. Accuracy of the estimated prevalence of obesity from self reported height and weight in an adult Scottish population. J Epidemiol Community Health. 2000;54(2):143-8.

12. Niedhammer I, Bugel I, Bonenfant S, Goldberg M, Leclerc A. Validity of selfreported weight and height in the French GAZEL cohort. Int J Obes Relat Metab Disord. 2000;24(9):1111-8.

13. Roberts RJ. Can self-reported data accurately describe the prevalence of overweight? Public Health. 1995;109(4):275-84

14. Spencer EA, Roddam AW, Key T. Accuracy of self-reported waist and hip measurements in 4492 EPIC-Oxford participants. Public Health Nutr. 2004;7(6):723-7.
15. Nawaz H, Chan W, Abdulrahman M, Larson D, Katz DL. Self-reported weight and height: Implications for obesity research. Am J Prev Med. 2001;20(4):294-8.

16. Rossouw K, Senekal M, Stander I. The accuracy of self-reported weight by overweight and obese women in an outpatient setting. Public Health Nutr. 2001;4(1):19-26.

17. Villanueva E. The validity of self-reported weight in US adults: a population based cross-sectional study. BMC Public Health. 2001;1:11.

18. Shields M, Gorber SC, Tremblay MS. Estimates of obesity based on self-report versus direct measures. Health Rep. 2008;19(2):1-16.

19. Nyholm M, Gullberg B, Merlo J, Lundqvist-Persson C, Råstam L, Lindblad U. The validity of obesity based on self-reported weight and height: Implications for population studies. Obesity (Silver Spring). 2007;15(1):197-208.

20. Madrigal H, Sanchez-Villegas A, Martinez-Gonzalez MA, et al. Underestimation of body mass index through perceived body image as compared to self-reported body mass index in the European Union. Public Health. 2000;114(6):468-73.

21. Lee SK. Validity of self-reported weight and height: Comparison between immigrant and non-immigrant Mexican Americans in NHANES III. $J$ Immigr Health. 2005;7(2):127-31.

22. Paeratakul S, White MA, Williamson DA, Ryan DH, Bray GA. Sex, race/ethnicity, socioeconomic status, and BMI in relation to self-perception of overweight. Obes Res. 2002;10(5):345-50

23. Brener ND, McManus T, Galuska DA, Lowry R, Wechsler H. Reliability and validity of self-reported height and weight among high school students. J Adolesc Health. 2003;32(4):281-7.

24. Calle EE, Teras LR, Thun MJ. Adiposity and physical activity as predictors of mortality. N Engl J Med. 2005;352(13):1381-4.

25. Reeves GK, Pirie K, Beral V, Green J, Spencer E, Bull D. Cancer incidence and mortality in relation to body mass index in the Million Women Study: cohort study. BMJ. 2007;335(7630):1134.

26. Flood V, Webb K, Lazarus R, Pang G. Use of self-report to monitor overweight and obesity in populations: some issues for consideration. Aust N Z J Public Health. 2000;24(1):96-9.

27. Taylor AW, Dal Grande E, Gill TK, et al. How valid are self-reported height and weight? A comparison between CATI self-report and clinic measurements using a large cohort study. Aust N Z J Public Health. 2007;30(3):238-46.

28. Harper P. National Health Survey: Summary of Results, 2007-2008. Canberra (AUST): Australian Bureau of Statistics; 2009. p. 1-64.

29. John U, Hanke M, Grothues J, Thyrian JR. Validity of overweight and obesity in a nation based on self-report versus measurement device data. Eur J Clin Nutr. 2005;60(3):372-7.

30. Bostrom G, Diderichsen F. Socioeconomic differentials in misclassification of height, weight and body mass index based on questionnaire data. Int J Epidemiol. 1997;26(4):860-6

31. Kuczmarski M, Kuczmarski R, Najjar M. Effects of Age on Validity of SelfReported Height, Weight, and Body Mass Index: Findings from the Third National Health and Nutrition Examination Survey, 1988-1994. J Am Diet Assoc. 2001;101(1):28-34.

32. Sahyoun NR, Maynard LM, Zhang XL, Serdula MK. Factors associated with errors in self-reported height and weight in older adults. J Nutr Health Aging. 2008;12(2):108-15.

33. 45 and Up Study Collaborators. Cohort Profile: The 45 and Up Study. Int $J$ Epidemiol. 2008;37(5):941-7.

34. World Health Organization. Obesity: Preventing and Managing the Global Epidemic. Geneva (CHE): WHO; 2000.

35. Bland J, Altman D. Statistical methods for assessing agreement between two methods of clinical measurement. Lancet. 1986;327(8476):307-10.

36. Landis JR, Koch GG. The measurement of observer agreement for categorical data. Biometrics. 1977;33(1):159-74.

37. Gillum RF, Sempos CT. Ethnic variation in validity of classification of overweight and obesity using self-reported weight and height in American women and men: the Third National Health and Nutrition Examination Survey. Nutr J. 2005;4:27.

38. Expert Subcommittee on the Use and Interpretation of Anthropometry in the Elderly. Uses and interpretation of anthropometry in the elderly in the assessment of physical status: report to the nutrition unit of the World Health Organization. J Nutr Health Ageing. 1998;2:5-17.

39. Armstrong M, Spencer E, Cairns B, et al. Body mass index and physical activity in relation to the incidence of hip fracture in postmenopausal women. $J$ Bone Miner Res. 2010 Dec15. PubMed PMID: 21162107.

40. Clarke R, Shipley M, Lewington S, et al. Underestimation of risk associations due to regression dilution in long-term follow-up of prospective studies. $\mathrm{Am} \mathrm{J}$ Epidemiol. 1999;150(4):341-53.

41. Manolio T, Collins R. Enhancing the feasibility of large cohort studies. JAMA 2010;304(20):2290-1

42. Mealing N, Banks E, Jorm L, Steel D, Clements M, Rogers K. Investigation of relative risk estimates from studies of the same population with contrasting response rates and designs. BMC Med Res Methodol. 2010;10(1):26.

43. Ponsonby A-L, Dwyer T, Couper D. Is this finding relevant? Generalisability and epidemiology. Aust N Z J Public Health. 1996;20(1):54-6. 